\title{
The Behavior-Physiology Nexus: Behavioral and Physiological Compensation Are Relied on to Different Extents between Seasons
}

\author{
Christine H. Basson \\ Susana Clusella-Trullas* \\ Centre for Invasion Biology, Department of Botany and \\ Zoology, Stellenbosch University, Private Bag X1, Matieland \\ 7602, South Africa
}

Accepted 3/7/2015; Electronically Published 5/14/2015

Online enhancements: supplementary figures and tables.

\begin{abstract}
Environmental variability occurring at different timescales can significantly reduce performance, resulting in evolutionary fitness costs. Shifts in thermoregulatory behavior, metabolism, and water loss via phenotypic plasticity can compensate for thermal variation, but the relative contribution of each mechanism and how they may influence each other are largely unknown. Here, we take an ecologically relevant experimental approach to dissect these potential responses at two temporal scales: weather transients and seasons. Using acclimation to cold, average, or warm conditions in summer and winter, we measure the direction and magnitude of plasticity of resting metabolic rate (RMR), water loss rate (WLR), and preferred body temperature $\left(T_{\text {pref }}\right)$ in the lizard Cordylus oelofseni within and between seasons. In summer, lizards selected lower $T_{\text {pref }}$ when acclimated to warm versus cold but had no plasticity of either RMR or WLR. By contrast, winter lizards showed partial compensation of RMR but no behavioral compensation. Between seasons, both behavioral and physiological shifts took place. By integrating ecological reality into laboratory assays, we demonstrate that behavioral and physiological responses of C. oelofseni can be contrasting, depending on the timescale investigated. Incorporating ecologically relevant scenarios and the plasticity of multiple traits is thus essential when attempting to forecast extinction risk to climate change.
\end{abstract}

Keywords: metabolism, water balance, phenotypic plasticity, ectotherm, thermal reaction norm, coadaptation, phenotypic integration.

*Corresponding author; e-mail: sct333@sun.ac.za.

Physiological and Biochemical Zoology 88(4):384-394. 2015. (C) 2015 by The University of Chicago. All rights reserved. 1522-2152/2015/8804-4137\$15.00. DOI: $10.1086 / 682010$

\section{Introduction}

The variability of environmental conditions across a range of timescales can impact physical performance, life-history tradeoffs, and evolutionary fitness of long-lived ectotherms. Indeed, seasonal and diurnal variation in environmental conditions (e.g., temperature) can constrain (or enhance) opportunities for behavioral and physiological compensation. The reliance of an organism on phenotypic plasticity also depends on the speed and magnitude of its response to changes in environmental conditions and how costly these responses are relative to the loss of fitness incurred by not having the response (e.g., DeWitt et al. 1998; Angilletta 2009; Reed et al. 2011). Therefore, to understand the impact of climate variability on individual performance or fitness costs, it is necessary to integrate environmental information with an individual's observed phenotypic responses, both behavioral and physiological. Thus, a behavior-physiology nexus occurs, with few studies attempting to integrate these types of information to understand field population dynamics (e.g., review in Angilletta et al. 2006). An integrated understanding of an organism's physiological and behavioral responses is critical for forecasting population responses to climate change, determining the ability of vulnerable species to tolerate climate variation, and understanding interactions between species, their local environmental conditions, and potential fitness impacts. Although much emphasis has been given to the central tendency of performance curve parameters when predicting responses of ectotherms to climate change (typically, critical thermal limits and temperature dependence of growth or running speed; e.g., Deutsch et al. 2008; Huey et al. 2009), fewer studies incorporate the contributions of physiological and behavioral plasticity, especially at ecologically relevant scales (Somero 2010; Reed et al. 2011; Gvoždík 2012). In particular, an individual may undergo shifts in its thermoregulatory behavior, metabolism, and water loss to compensate for thermal variation, but the relative contribution of each mechanism toward this compensation and the temporal scales at which these shifts may occur (extreme events, weather fronts, or seasons) are largely unknown (but see Glanville and Seebacher 2006).

Lizards are excellent models to explore behavioral and physiological plasticity of ectotherms in response to climate variability because they are the focus of both local and global analyses of species vulnerability to climate change (Huey et al. 2009; Sinervo et al. 2010), they depend to a large extent on their microenvironment and behavioral adjustments (body orientation, posture, and shuttling) to maintain optimal body temperature, and they are the focus of most empirical and theoretical tests of thermal responses in ectotherms (Angilletta 
2009). Typically, the performance traits of an ectotherm described as a function of body temperature have an asymmetrical shape that peaks at the preferred body temperature (targeted temperature selected in a thermal gradient devoid of biotic factors, $T_{\text {pref }}$ ) but rapidly drops at temperatures higher than $T_{\text {pref }}$. At $T_{\text {pref }}$, most (but not all) physiological and biological processes are optimized (enzyme activity, energy assimilation, sprinting; Licht 1964; Hertz et al. 1983; but see Angilletta et al. 2002) and likely enhance individual fitness (Cowles and Bogert 1944; Huey and Bennett 1987; Angilletta et al. 2006). However, when targeting $T_{\text {pref }}$, thermoregulatory behaviors can rapidly become energetically expensive, especially during periods or in habitats of poor thermal quality (Huey and Slatkin 1976; Lee 1980). Plastic responses in the form of acclimation or acclimatization of biochemical processes underlying optimal performance - and thus $T_{\text {pref }}$ - may compensate for climate variation and favor performance while minimizing costs and optimizing activity periods in suboptimal conditions (Hadamová and Gvoždík 2011).

Seasonal shifts in $T_{\text {pref }}$ (acclimatization) have been reported, but responses to shorter exposures (e.g., acclimation) have found contrasting results (e.g., Wheeler 1986; Kaufmann and Bennett 1989; reviewed in Clusella-Trullas and Chown 2014). In general, $T_{\text {pref }}$ is thought to be largely conserved among lizards, possibly due to the Bogert effect (Huey et al. 2003), whereby the evolution of physiological traits is constrained as a result of behavioral adjustments that minimize selection on physiology (Losos et al. 2004). Recently, Gvoždík (2012) suggested three likely reasons for which the plasticity of $T_{\text {pref }}$, although existent in some species, has largely been overlooked: (1) acclimation exposures typically lack biological reality (e.g., no diel fluctuations as in natural regimes), (2) the magnitude of acclimation responses is typically small (but nonetheless significant), and (3) reactive thermoregulatory adjustments may be considered more important than plastic responses. Furthermore, changes at the cellular biochemical level underlying $T_{\text {pref }}$ shifts may result in high energetic costs, and other compensatory responses may take place. For example, under a warmer thermal regime, an increased $T_{\text {pref }}$ may have detrimental consequences for the individual, since the margin between $T_{\text {pref }}$ and the critical thermal maximum $\left(\mathrm{CT}_{\max }\right)$ is typically small, and $T_{\text {pref }}$ is generally maintained below $T_{\text {opt }}$ (Martin and Huey 2008). Instead, $T_{\text {pref }}$ may not shift under warm conditions, but the thermal sensitivity of physiological traitssuch as maintenance metabolism, a key factor that sets resource uptake rates for survival, growth, reproduction, and, therefore, overall performance and fitness (McNab 2002; Burton et al. 2011) - may compensate for temperature changes by lowering energetic costs (Tsuji 1988a). Similarly, shifts in $T_{\text {pref }}$ can be associated with selection of drier sites and thus can have implications for water balance of the organism. Therefore, the plasticity of temperature selection may be inseparable from the complex temperature dependence and acclimation responses of metabolism and water balance (in both the intercepts and the slopes of these reactions norms). Indeed, understanding beneficial (adaptive) acclimation responses requires exami- nation of several traits concomitantly, not just one (Kingsolver and Huey 1998; Woods and Harrison 2001; Glanville and Seebacher 2006), and may facilitate an understanding of selection pressures operating on them and the mechanisms underlying the responses. For example, compensation of physiological traits is costly in terms of time and energy required to synthesize proteins and other cellular processes (e.g., rates of transcription; Somero 1978; Angilletta et al. 2006; Rogers et al. 2007; Burton et al. 2011), which may limit the magnitude of plasticity of these traits. Overall, little is known about which behavioral and/or physiological acclimatory responses or combinations thereof can be expected under different climate regimes.

In thermally variable environments, lizard species that hibernate typically lower energetic costs when resources are scarce (Congdon et al. 1979), whereas species that stay active in winter generally have an increased resting metabolic rate (RMR; Tsuji 1988a). The latter is in line with the thermal compensation or metabolic cold adaptation hypothesis, whereby individuals exposed to a cold temperature regime maintain a higher RMR than warm-exposed individuals when tested at a common intermediate temperature ( $\mathrm{McNab}$ 2002). At the intraspecific level, a high RMR may promote the maintenance of accelerated physiological reactions and enable lizards to perform activities such as thermoregulation and foraging during short windows of opportunity in cold suboptimal environments (for review, see Tsuji 1988a; Hare et al. 2010) and is likely dependent on the availability of resources (Clarke 1993, 2003; Burton et al. 2011). In summer, the evidence that a lower RMR could reduce energetic costs (Tsuji 1988a; Christian and Green 1994) or decrease water loss when water resources are scarce (Claussen 1967; Case 1976) is more limited, perhaps suggesting that behavioral compensation buffers to a larger extent climatic challenges. Alternatively, if water is available, evaporative cooling via selection of warm microsites may be a complementary strategy to maintain optimal temperatures and enhance fitness. Therefore, the integration of multipletrait plastic responses is essential for a better understanding of adaptive phenotypic plasticity.

This study aims to take a novel approach when investigating the contributions of phenotypic plasticity of behavioral and physiological traits to environmental change. Specifically, we assess the direction and magnitude of behavioral and physiological plasticity displayed by animals exposed to environmental variability at two different temporal scales: short-term (such as during transient weather fronts) and long-term (between summer and winter seasons). To increase ecological relevance in the interpretation of plastic responses, we define acclimation treatments from field operative temperature $\left(T_{\mathrm{e}}\right)$ distributions, examine thermal habitat quality and behavioral thermoregulation in the field, and assess prey diversity and abundance as a measure of resources available in summer and winter. To achieve these aims, the thermal acclimation responses of $T_{\text {pref }}, \mathrm{RMR}$, and water loss rate (WLR) were determined using the lizard Cordylus oelofseni (Mouton and van Wyk 1990). Cordylus oelofseni is a diurnal, temperate, vivip- 
arous lizard that inhabits rock outcrops and maintains activity throughout winter. It is endemic to only three mountain tops in the Western Cape Province of South Africa and is likely vulnerable to climatic change (Mouton and van Wyk 1990). More generally, cordylid lizards are good thermoregulators (Clusella-Trullas et al. 2009) and have relatively long life spans ( 10-20 yr; Fogel 2003) and thus should experience substantial seasonal and interannual variation within generations, making this species an excellent model to investigate the plasticity of these traits and potential compensatory roles thereof.

\section{Material and Methods}

\section{Lizard Collection and Maintenance}

Lizards were collected ( 21 males, 21 females) from Landroskop $\left(34^{\circ} 02^{\prime} \mathrm{S}, 19^{\circ} 00^{\prime} \mathrm{E}\right.$, altitude $1,080 \mathrm{~m}$ asl) in the Hottentots Holland Mountains, Western Cape Province, South Africa, in winter (August 2011) and summer (January 2012), and the same set of experiments (metabolism, WLR, and preferred body temperature) was repeated in both seasons. Lizards were individually marked with nontoxic paint and transported to the laboratory to begin acclimation treatments within $48 \mathrm{~h}$. Individuals were maintained in dark cloth bags within a cooler box during transport to minimize stress and heat. Ticks and mites were found on summer-collected lizards and removed before experimental procedures.

After determining body mass $\left(M_{\mathrm{b}}\right.$, analytical balance $\pm 0.0001 \mathrm{~g}$; AX504, Mettler Toledo International), sex, and snout-vent length, lizards were housed in terrariums (9.5-L plastic containers with mesh tops, maximum of four individuals per container) with stone/sand substrate and artificial refuges and placed within a temperature-controlled incubator (Sanyo Cooled Incubator, MIR-254, Sanyo Electric). Water was supplied ad lib., while food (gray crickets Acheta domestica and superworms Zophobas morio) was given once a week during winter and twice a week during summer. Ultraviolet (UV) light was provided daily, and the containers were rotated on a weekly basis to ensure that all lizards were equally exposed to acclimation treatment and UV-B radiation. We measured individual $M_{\mathrm{b}}$ weekly in order to monitor lizard condition.

\section{Seasonal Thermal Regimes and Acclimations}

At the study site, 26 copper models of the same size, shape (including legs and tail), and reflectance as Cordylus oelofseni (for model construction and calibrations, see Clusella-Trullas et al. 2009) were placed randomly in a variety of microhabitats (sun, shade, and crevice), orientations, and postures. They were instrumented with thermocouples (Type T, 24SWG, Omega Engineering, Stamford, CT) and connected to a data logger (CR1000 and 32 channel multiplexer, Campbell Scientific, Utah) to measure and record the operative temperatures $\left(T_{\mathrm{e}}\right)$ of $C$. oelofseni in its habitat at an hourly rate. Acclimation treatments were based on $T_{\mathrm{e}}$ data from summer (January-March) and winter (June-August) of 2005, 2011, and 2012, mimicking the diel cycles experienced by lizards for each season (table 1). Lizard body temperatures are typically maintained within the range of $T_{\mathrm{e}}$ recorded in the field (Clusella-Trullas et al. 2009).

Lizards were first exposed for 1 wk to the average acclimation treatment for that season (summer or winter) and then split into three acclimation treatments (cold, average, and warm; table 1) with 14 lizards per treatment (seven males, seven females). Lizards were maintained at these treatments for $2 \mathrm{wk}$ (i.e., simulating a short-term environmental change) before the first respirometry (metabolism and water loss) trials started. They were subsequently kept in the same acclimation treatment conditions until all respirometry and $T_{\text {pref }}$ trials were completed (ca. 1 mo). Data loggers (Maxim Hygrochron iButtons, DS1923, Sunnyvale, CA) were used to record temperatures every $10 \mathrm{~min}$ in all acclimation treatment and experimental setups. Ethical clearance for all procedures was given by Stellenbosch University (11NP_BAS01).

\section{Respirometry}

RMR and WLR were determined using a calibrated LI-COR infra-red $\mathrm{CO}_{2} / \mathrm{H}_{2} \mathrm{O}$ analyzer (Li-7000, LI-COR, Lincoln, NE) set in gas flow-through configuration and plumbed in differential mode following established methods (Lighton 2008) (fig. A1; figs. A1, A2 available online). A glass respirometry cuvette $(180 \mathrm{~mL})$ was darkened to increase quiescence of lizards and kept in an incubator (Sanyo Cooled Incubator, MIR-153, Sanyo Electric) at one of three test temperatures for $1 \mathrm{~h}\left(10^{\circ}, 20^{\circ}\right.$, and $30^{\circ} \mathrm{C}$; verified using a thermocouple and recorder TC 1000; Sable Systems, Las Vegas, NV) and maintained within $1^{\circ} \mathrm{C}$ of the target temperature. Compressed air from a gas cylinder $\left(21 \% \mathrm{O}_{2}\right)$ was scrubbed of any potential water and $\mathrm{CO}_{2}$ using silica gel:drierite and soda lime, respectively. This scrubbed gas then flowed through a mass flow control valve (Side-Track Model 840, Sierra Instruments, Monterey, CA) linked to a mass flow control unit (Intelligent Mass Flow Control Unit, MFC-2, Sable Systems) at a rate of $200 \mathrm{~mL} \mathrm{~min}^{-1}$. A baseline recording was done at the beginning and at the end of each respirometry run, and span gas of 0 and $395 \mathrm{ppm} \mathrm{CO}_{2}$ and 0 and $0.876 \mathrm{kPa} \mathrm{H}_{2} \mathrm{O}$ (at $5^{\circ} \mathrm{C}$ from dewpoint generator) were used for calibrations. A 1- $\mathrm{Hz}$ sampling rate was captured by the LI-COR software and processed with Expedata (ver. 1.0.24; Sable Systems) by transforming ppm $\left(\mathrm{CO}_{2}\right)$ and ppt $\left(\mathrm{H}_{2} \mathrm{O}\right)$ recorded during periods of inactivity to $\mathrm{mL} \mathrm{CO} \mathrm{CO}_{2} \mathrm{~h}^{-1}$ and $\mathrm{mg} \mathrm{H}_{2} \mathrm{O} \mathrm{h}^{-1}$, using standard equations (Lighton 2008). Each individual was tested at the three test temperatures in a randomized order, resulting in a total of 126 trials (trial duration mean $\pm \mathrm{SD}=44.1 \pm 9.8$ min). Periods of RMR and WLR were identified as minimum stable periods in the gas exchange trace and matched quiescence as observed in pilot trials. Given C. oelofseni's rock-dwelling and sit-andwait lifestyle, which is typically associated with low metabolic rate, 30 min of recording were found to reflect RMR in this species, since lizards readily rested in the experimental cuvettes and maintained a stable metabolic profile throughout all 
Table 1: Summary of operative temperatures $\left(T_{\mathrm{e}}\right)$ from 26 lizard copper models and laboratory acclimation treatments in summer and winter

\begin{tabular}{|c|c|c|c|c|}
\hline \multirow[b]{2}{*}{ Season } & \multicolumn{2}{|c|}{ Field operative temperature $\left(T_{\mathrm{e}} ;{ }^{\circ} \mathrm{C}\right)$} & \multicolumn{2}{|c|}{ Acclimation treatment $\left({ }^{\circ} \mathrm{C}\right)$} \\
\hline & Day & Night & Day & Night \\
\hline \multicolumn{5}{|l|}{ Winter: } \\
\hline Minimum/cold & 6.44 & 4.33 & $10.26 \pm .37(10)$ & $7.48 \pm .28(7)$ \\
\hline Average & $12.09 \pm 1.41$ & $7.06 \pm .71$ & $14.42 \pm .47(15)$ & $7.09 \pm .40(7)$ \\
\hline Maximum/warm & 16.64 & 9.22 & $19.61 \pm .75(20)$ & $7.43 \pm .38(7)$ \\
\hline \multicolumn{5}{|l|}{ Summer: } \\
\hline Minimum/cold & 15.77 & 13.35 & $19.93 \pm .70(20)$ & $15.39 \pm .57(15)$ \\
\hline Average & $22.62 \pm 1.66$ & $15.66 \pm .68$ & $24.24 \pm .36(25)$ & $15.06 \pm .90(15)$ \\
\hline Maximum/warm & 28.10 & 18.06 & $29.06 \pm .53(30)$ & $15.00 \pm .41(15)$ \\
\hline
\end{tabular}

recordings. The typical calm behavior in respirometry cuvettes meant that any potential enhancement of $\dot{\mathrm{V}} \mathrm{CO}_{2}$ resulting from lactate buildup from activity was highly unlikely. Lizards were fasted for $48 \mathrm{~h}$ and given $15 \mathrm{~min}$ to equilibrate to the test temperature before trials started. Each lizard was weighed before and after each trial.

\section{Preferred Body Temperature}

Five temperature gradients $\left(12^{\circ}-55^{\circ} \mathrm{C}\right.$, verified using calibrated copper models) were created within a temperaturecontrolled room (set at $12^{\circ} \mathrm{C}$ for the cold ends) and infrared lights at the warm ends ( $175 \mathrm{~W}$; General Electric, Johannesburg). These lights were suspended ca. $30 \mathrm{~cm}$ from the ground at each end of five $180 \times 30-\mathrm{cm}$ plywood rectangles (with stones as substrate). Thin thermocouples (Type T, 36SWG) were inserted into the lizard cloaca and secured around the tail, allowing free movement of single lizards in each gradient. Body temperatures were logged at 5-min intervals (from 0930 to 1600 hours) using a CR1000 data logger. Water was provided ad lib. and placed ca. $10 \mathrm{~cm}$ from the cold end of the box, and lizard $M_{\mathrm{b}}$ was taken before and after $T_{\text {pref }}$ trials.

\section{Field Lizard Activity and Prey Availability}

To assess the abundance and activity patterns of C. oelofseni in the field, the same observer walked two 100-m transects daily at $0800,1000,1200,1500$, and 1800 hours for $4 \mathrm{~d}$ during summer (January) and winter (August). Lizards observed within $10 \mathrm{~m}$ on either side of transects were counted and activities recorded (e.g., basking, walking, mating, running). Prey availability was determined by use of 21 pitfall traps (200-mL containers with 75\% EtOH and soap; Zytynska et al. 2011) and net sweeping (Clusella-Trullas and Botes 2007) from 0800 to 1800 hours for $5 \mathrm{~d}$ each season to match lizard activity periods.

\section{Statistical Analysis}

For summer, only nongravid females (and male lizards) were included in the analyses to refrain from introducing additional effects of reproduction on RMR and WLR. RMR $\left(\dot{\mathrm{V}}_{2} \mathrm{~mL} \mathrm{~h}^{-1}\right)$ was $\log$ transformed to improve model diagnostics (Zuur et al. 2009) and analyzed using a general mixed effects model (GLMM, nlme package; Pinheiro et al. 2013) for each season (summer and winter) separately, with acclimation treatment, test temperature, sex, and $M_{\mathrm{b}}$ as fixed predictors and lizard identity as a random factor. WLR $\left(\dot{\mathrm{V}}_{2} \mathrm{O} \mathrm{mg} \mathrm{h}^{-1}\right)$ was similarly analyzed. Differences in RMR and WLR between winter and summer lizards were also assessed using data at test temperatures of $10^{\circ}, 20^{\circ}$, and $30^{\circ} \mathrm{C}$ separately. For the latter, the residuals from the regression of RMR and WLR against average $M_{\mathrm{b}}$ were used as dependent variables (to account for differences in mass across individuals) and analyzed using generalized linear models (GLZ with Gaussian family and identity link), with season, acclimation treatment, and sex as predictors. To further explore seasonal effects, we compared data at all test temperatures from the $20^{\circ} \mathrm{C}$ acclimation treatment only (common acclimation treatment to both seasons), using GLMM (RMR or WLR as the dependent variable; season, test temperature, $M_{\mathrm{b}}$, and sex as fixed factors; and lizard identity as the random factor). For all analyses, body mass was taken as the mean between pre- and post-trial mass measurements.

The central $50 \%$ of thermal gradient data was used to determine the mean, minimum (twenty-fifth quartile), maximum (seventy-fifth quartile), and range of $T_{\text {pref }}$, since extreme values (table A1; tables A1-A3 available online) were considered to be lizard exploratory behavior (Hertz et al. 1993). GLZ models (with Gaussian family and identity link function) were used to analyze $T_{\text {pref }}$ data. Mean, minimum, maximum, and range of $T_{\text {pref }}$ selected were the dependent variables, and season, acclimation treatment, and sex were the predictors. $M_{\mathrm{b}}$ was treated as a continuous variable in all analyses. 
For each season, $\left(\bar{d}_{\mathrm{e}}\right)$ was calculated as the deviance of $T_{\mathrm{e}}$ from $T_{\text {pref }}\left(\bar{d}_{\mathrm{e}}=T_{\text {pref }}-T_{\mathrm{e}}\right.$; Hertz et al. 1993), using $T_{\mathrm{e}}$ data taken from 3 mo of summer (January-March 2012) and winter (JuneAugust 2011). Smaller values of $\bar{d}_{\mathrm{e}}$ reflect better habitat quality (i.e., available microsite temperatures are closer to preferred body temperatures), and summer and winter $\left(\bar{d}_{\mathrm{e}}\right)$ were compared using two-sample $t$-tests. For comparisons of prey abundance and diversity between seasons, arthropods were identified to the family level, with species assigned identification numbers and used to calculate Shannon-Wiener's measure of diversity $\left(H^{\prime}\right)$, Simpson's evenness measure $\left(E_{1 / D}\right)$, and Berger-Parker's dominance index $(d)$.

All statistical analyses were conducted in R (ver. 2.15.0; $\mathrm{R}$ Development Core Team 2008). Means \pm SEM were reported, unless indicated otherwise, and the significance level was set at $\alpha<0.05$. Outliers were identified from plots of standardized residuals versus fitted values and Cook's distance criteria (e.g., Zuur et al. 2009; total of seven outliers). All results presented in tables are minimal adequate models based on the Akaike information criterion (AIC), and GLMMs were compared using maximum likelihood (Crawley 2007; Zuur et al. 2009). Full models with all interactions were reduced using a backward stepwise model simplification to obtain minimum adequate models; models with $\triangle \mathrm{AIC}$ (model AIC minus that of the best-fit model) $<2$ were considered as acceptable alternative models, models with $4 \leq \Delta \mathrm{AIC} \leq 7$ had considerably less support, and models with $\Delta$ AIC $>10$ had no support (Burnham and Anderson 2001). We verified that models with a random parameter were better models than generalized least squares models for each response variable, following the methods of Zuur et al. 2009.

\section{Results}

\section{Metabolism and Water Loss}

In summer, both RMR and WLR were significantly positively related to test temperature and body mass $\left(M_{\mathrm{b}}\right)$. However, acclimation treatment did not have an effect on these response variables (table 2; fig. $1 A$ for RMR). The lack of an acclimation treatment $\times$ test temperature effect indicates that the $\mathrm{Q}_{10}$ was unaffected $\left(3.27\right.$ at $20^{\circ} \mathrm{C}, 3.28$ at $25^{\circ} \mathrm{C}$, and 3.22 at $\left.30^{\circ} \mathrm{C}\right)$. In winter, both RMR and WLR increased significantly with test temperature and $M_{\mathrm{b}}$ (table 2). For RMR, acclimation treatment and acclimation treatment $\times$ test temperature effects were significant. The interaction indicated that individuals acclimated at the warmest acclimation treatment $\left(20^{\circ} \mathrm{C}\right)$ had a higher RMR than individuals acclimated to $10^{\circ}$ and $15^{\circ} \mathrm{C}$ at the lowest test temperature $\left(10^{\circ} \mathrm{C}\right)$, whereas individuals acclimated at $10^{\circ} \mathrm{C}$ had a higher RMR than individuals acclimated to $15^{\circ}$ or $20^{\circ} \mathrm{C}$ at the warmest test temperature $\left(30^{\circ} \mathrm{C}\right.$; table 2; fig. $1 B$ ). The acclimation treatment $\times$ test temperature interaction is also illustrated by differences in $\mathrm{Q}_{10}$ varying from 5.73 at the $10^{\circ} \mathrm{C}$ acclimation treatment, 4.19 at $15^{\circ} \mathrm{C}$, and 3.07 at $20^{\circ} \mathrm{C}$.

Between seasons, mean $M_{\mathrm{b}}$ of male lizards did not differ $(6.75 \pm 0.21$ and $6.43 \pm 0.22 \mathrm{~g}$ for winter and summer, re-
Table 2: General mixed effects model outputs for the effect of test temperature $\left({ }^{\circ} \mathrm{C}\right)$, acclimation treatment $\left({ }^{\circ} \mathrm{C}\right)$, body mass $\left(M_{\mathrm{b}} ; \mathrm{g}\right)$, and sex on resting metabolic rate $\left(\log _{10} \dot{\mathrm{V}} \mathrm{CO}_{2} ; \mathrm{mL} \mathrm{h}^{-1}\right)$ and water loss rate $\left(\dot{\mathrm{V}}_{2} \mathrm{O} ; \mathrm{mg} \mathrm{h}^{-1}\right)$ of summer- and wintercollected lizards

\begin{tabular}{lrrr}
\hline Season and coefficient & Estimate & SE & $\mathrm{df}$ \\
\hline Summer: & & & \\
Resting metabolic rate: & & & \\
$\quad$ Intercept & -2.64 & .11 & 50 \\
Test temperature & .05 & .002 & 50 \\
$M_{\mathrm{b}}$ & .10 & .02 & 50 \\
Water loss rate: & & & \\
Intercept & -1.14 & 3.13 & 46 \\
Test temperature & .21 & .05 & 46 \\
$M_{\mathrm{b}}$ & 1.06 & .50 & 46 \\
Winter: & & & \\
Resting metabolic rate: & & & \\
Intercept & -3.35 & .30 & 80 \\
Acclimation treatment & .05 & .02 & 80 \\
Test temperature & .10 & .01 & 80 \\
$M_{\mathrm{b}}$ & .06 & .02 & 80 \\
Acclimation treatment $\times$ test & & & \\
$\quad$ temperature & -.003 & .0007 & 80 \\
Water loss rate: & & & \\
Intercept & -2.11 & 1.59 & 79 \\
Test temperature & .31 & .02 & 79 \\
$M_{\mathrm{b}}$ & .44 & .22 & 79 \\
\hline
\end{tabular}

Note. Minimum adequate models are presented (see "Material and Methods").

spectively; $t_{46}=-1.06, P>0.2973$ ), but female lizards from the winter population were significantly heavier and larger than the nongravid females from the summer population (mass: $7.09 \pm 0.31$ and $5.55 \pm 0.22 \mathrm{~g}$ for winter and summer, respectively; $t_{39}=-3.29, P=0.0033$; snout-vent length: $61.57 \pm 0.84$ and $56.70 \pm 1.43 \mathrm{~mm}$ for winter and summer, respectively; $\left.t_{39}=-2.92, P=0.0103\right)$. At the test temperatures of $20^{\circ}$ and $30^{\circ} \mathrm{C}$, mass-adjusted RMR was higher in winter $\left(t_{1,67}=2.17, P=0.0333\right)$ than in summer $\left(t_{1,64}=\right.$ 2.71, $P=0.0089$ ), and at the test temperature of $30^{\circ} \mathrm{C}$, an interaction between acclimation treatment and season $\left(t_{1,64}=\right.$ $-2.28, P=0.0262)$ reflected differences in the slopes of RMR and acclimation treatment: no effect of acclimation treatment in summer but an increase in RMR of cold-acclimated lizards relative to warm-acclimated ones in winter (fig. 1). By contrast, at the test temperature of $10^{\circ} \mathrm{C}$, mass-adjusted RMR was slightly lower in winter than in summer $\left(t_{1,68}=-2.27, P=\right.$ 0.0266), and while RMR did not change with acclimation treatment in summer, warm-acclimated lizards had a higher RMR than cold-acclimated ones in winter (season $\times$ acclimation treatment interaction: $\left.t_{1,68}=2.71, P=0.0086\right)$. At test temperatures of $10^{\circ}$ and $20^{\circ} \mathrm{C}$, mass-adjusted WLR did not differ between summer $\left(t_{1,68}=-1.24, P=0.2199\right)$ and winter $\left(t_{1,66}=-0.033, P=0.9740\right)$, but at the test temperature of 

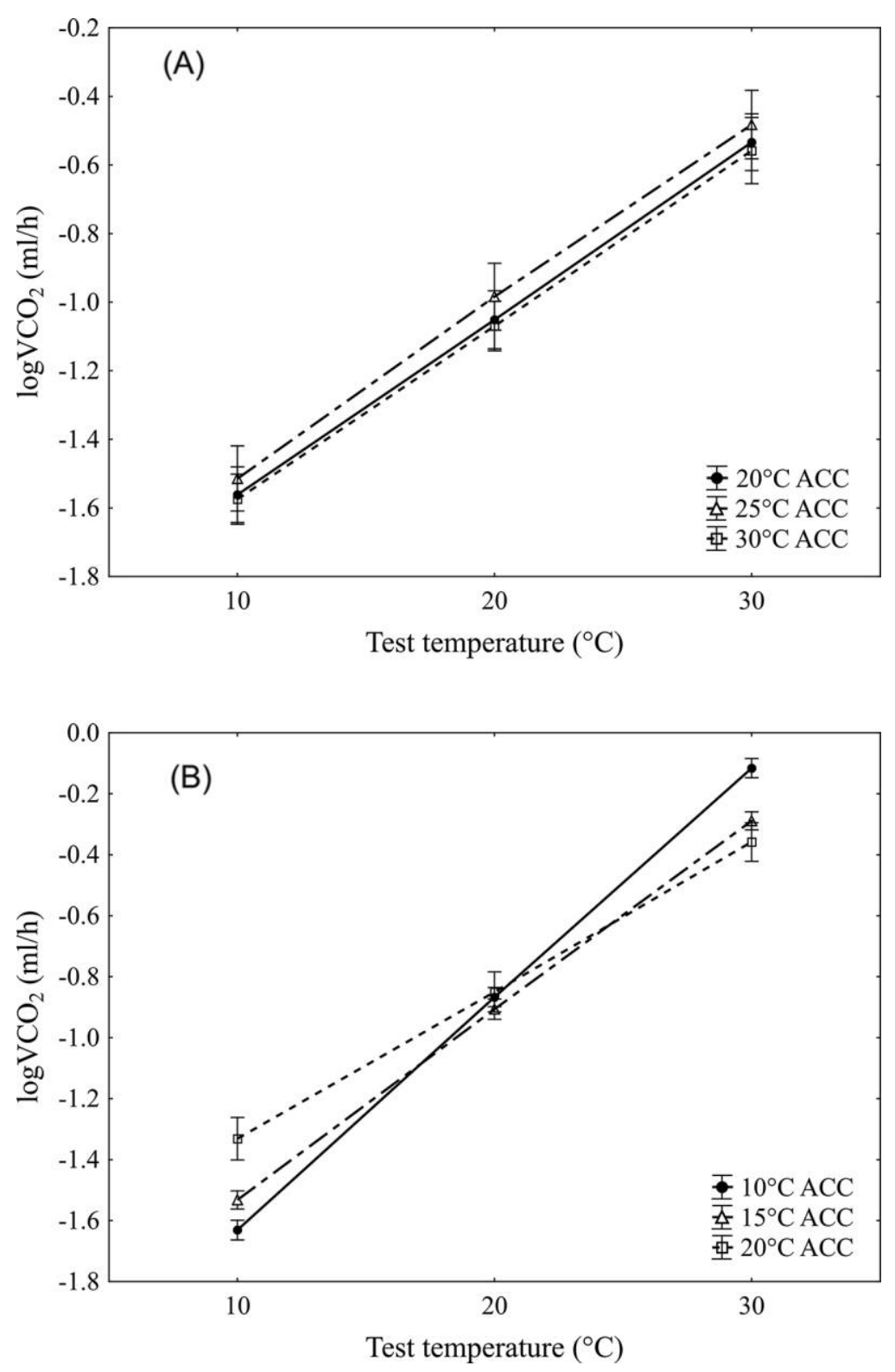

Figure 1. Test temperature effects on resting metabolic rate $\left(\log _{10} \dot{\mathrm{V}} \mathrm{CO}_{2}\right)$ of lizards collected in summer and acclimated to cold $\left(20^{\circ} \mathrm{C}\right)$, average $\left(25^{\circ} \mathrm{C}\right)$, or warm $\left(30^{\circ} \mathrm{C}\right)$ temperatures $(A)$ and lizards collected in winter and acclimated to cold $\left(10^{\circ} \mathrm{C}\right)$, average $\left(15^{\circ} \mathrm{C}\right)$, or warm $\left(20^{\circ} \mathrm{C}\right)$ temperatures $(B$; for detailed thermal regimes, see table 1$)$. Data shown are estimates from the general mixed effects model. Boxes represent means \pm SEM, and whiskers are $\pm 95 \%$ confidence intervals. ACC, acclimation treatment.

$30^{\circ} \mathrm{C}$, mass-adjusted WLR in winter was significantly lower than in summer-collected lizards $\left(t_{1,57}=-2.71, P=0.0090\right)$. When we examine seasonal differences for individuals exposed to the same $20^{\circ} \mathrm{C}$ acclimation treatment, RMR did not differ between seasons, but winter lizards had a lower WLR than lizards in summer (table 3). Original data means are presented in table A2.

\section{Preferred Body Temperature}

In summer, lizards in the warmest acclimation treatment selected a lower mean and maximum $T_{\text {pref }}$ compared with the cold acclimation treatment (mean $T_{\text {pref }}: t_{2,23}=-2.29, P=$ 0.0315 ; maximum $T_{\text {pref }}: t_{2,23}=-3.22, P=0.0038$ ). Mean $T_{\text {pref }}$ was $31.57^{\circ} \pm 0.72^{\circ}$ and $33.60^{\circ} \pm 0.54^{\circ} \mathrm{C}$ and maximum $T_{\text {pref }}$ was $32.86^{\circ} \pm 0.50^{\circ}$ and $34.80^{\circ} \pm 0.36^{\circ} \mathrm{C}$ for the warm and cold acclimation treatments, respectively. For both mean and maximum $T_{\text {pref, }}$, warm and average acclimation treatment $T_{\text {pref }}$ did not differ $\left(t_{2,23}=-0.96, P=0.345 ; t_{2,23}=-1.85, P=\right.$ 0.0768 , respectively). $M_{\mathrm{b}}$ and sex did not affect mean or maximum $T_{\text {pref. }}$ In winter, none of the predictor variables had an effect on mean, maximum, minimum, or range of $T_{\text {pref }}$.

Between seasons, winter lizards selected lower mean $\left(t_{1,61}=\right.$ $-2.24, P=0.0292)$ and minimum $T_{\text {pref }}\left(t_{1,60}=-2.10, P=\right.$ 
Table 3: General mixed effects model outputs for the effects of season, test temperature, body mass $\left(M_{\mathrm{b}}\right)$, and sex on resting metabolic rate and water loss rate in lizards from the $20^{\circ} \mathrm{C}$ acclimation groups only

\begin{tabular}{lrll}
\hline Coefficient & Estimate & SE & df \\
\hline Resting metabolic rate: & & & \\
$\quad$ Intercept & -2.74 & .14 & 43 \\
Season (winter) & .11 & .06 & 43 \\
Test temperature & .05 & .003 & 43 \\
$M_{\mathrm{b}}$ & .12 & .02 & 43 \\
Water loss rate: & & & \\
Intercept & -.76 & 2.23 & 43 \\
Season (winter) & -5.02 & .97 & 43 \\
Test temperature & .27 & .05 & 43 \\
$M_{\mathrm{b}}$ & .99 & .35 & 43 \\
\hline
\end{tabular}

Note. Minimum adequate models are presented (see "Material and Methods")

0.0404) than did summer lizards (all acclimation treatment mean $T_{\text {pref }}: 32.00^{\circ} \pm 0.40^{\circ}$ and $33.04^{\circ} \pm 0.29^{\circ} \mathrm{C}$; minimum $T_{\text {pref }}: 30.29^{\circ} \pm 0.49^{\circ}$ and $31.71^{\circ} \pm 0.34^{\circ} \mathrm{C}$ for winter and summer, respectively). A significant interaction for mean $T_{\text {pref }}$ between season and acclimation treatment $\left(t_{1,61}=2.05, P=\right.$ 0.0449) reflects the difference in the relationship between mean $T_{\text {pref }}$ and acclimation treatments in summer and winter (fig. 2).

\section{Lizard Field Activity and Thermal Constraints}

From transects, 147 and 597 lizards were observed in winter and summer, respectively. During both seasons, most lizards basked (only $10 \%$ and $12 \%$ of lizards were moving at the time of observation in winter and summer, respectively). In winter, $52.4 \%$ of lizards were observed between 1200 and 1300 hours (fig. $3 A$ ), whereas in summer, lizards were observed over a larger portion of the day, from 0800 to 1800 hours, with a peak at 1000 hours $(31.3 \%$ of lizards observed; fig. $3 B$ ). In summer, the $\bar{d}_{\mathrm{e}}$ index for the warm acclimation treatment lizards $\left(12.17^{\circ} \pm 0.15^{\circ} \mathrm{C}\right)$ was significantly lower (i.e., thermal habitat quality higher) than cold acclimation treatment lizards $\left(14.17^{\circ} \pm 0.15^{\circ} \mathrm{C} ; t_{0.05(2), 3,770}=-9.28, P=0.0001^{-16}\right)$. Winter $\bar{d}_{\mathrm{e}}\left(23.12^{\circ} \pm 0.10^{\circ} \mathrm{C}\right)$ was significantly higher than summer $\left(t_{0.05(2), 4,078}=116.19, P=0.0001^{-16} ; t_{0.05(2), 4,078}=107.38, P=\right.$ $0.0001^{-16}$ for winter and cold-acclimated summer lizards and winter and warm-acclimated summer lizards, respectively). Prey diversity and abundance in summer and winter indicated that resources consumed by Cordylus oelofseni were available in both seasons (table A3). Invertebrate species diversity $\left(H^{\prime}=\right.$ 2.58 and 2.86 for summer and winter, respectively) and evenness $\left(E_{1 / D}=0.10\right.$ and 0.34 for summer and winter, respectively) were lower in summer than in winter, but dominance of a single family was higher in summer $(d=0.34)$ than in winter $(d=$ 0.22). Total abundance was 952 individuals (29 taxonomic families) in summer and 207 individuals (25 families) in winter, with ants being the most abundant in both seasons (table A3).

\section{Discussion}

In this study, we integrated ecological reality (daily temperature dynamics and seasonal variation) into the determination of responses of several traits to thermal acclimation regimes and found that the precise trait responses of thermoregulation, energetics, and WLR can be complex and variable, depending on the conditions and scale investigated. In the short-term, behavioral rather than physiological compensation takes place in summer, while partial compensation of MR appears to be more significant than behavioral responses in winter. When lizard responses are compared between seasons, both behavioral and physiological shifts take place: in summer, lizards selected overall lower $T_{\text {pref }}$ than lizards sampled in winter, and when physiological responses are compared at a common temperature near $T_{\text {pref }}\left(30^{\circ} \mathrm{C}\right)$, summer-collected lizards had a lower RMR but a higher WLR than winter-collected lizards. This study's approach therefore provides valuable insights into both the capacity and the limit of these organisms to buffer climate variation via phenotypic plastic responses and highlights the partitioning of several modes of compensation. Although stress-induced effects cannot entirely be discarded from experimental trials, we used protocols (e.g., darkened cuvettes, habituation periods, ecologically relevant test temperatures and acclimations) to minimize such effects. This integrative and ecologically relevant approach is essential for

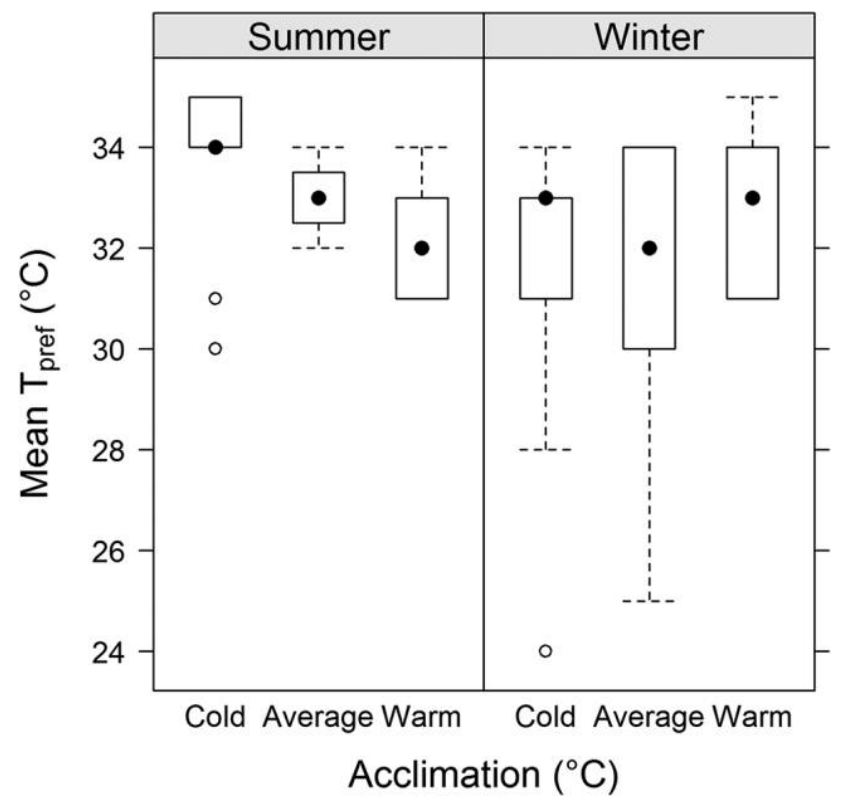

Figure 2. Winter-collected lizards selected lower mean $T_{\text {pref }}$ than summer-collected lizards. $T_{\text {pref }}$ did not differ across acclimation treatments in winter, but in summer, lizards from the warm acclimation treatment selected a significantly lower mean $T_{\text {pref }}$ than lizards from the other two acclimation treatments. Boxplots indicate the median (circles), first and third quartiles, and extreme values (whiskers; unless outliers are present). Cold, average, and warm acclimations refer to the thermal regimes described in table 1, which differ between summer and winter. A color version of this figure is available online. 

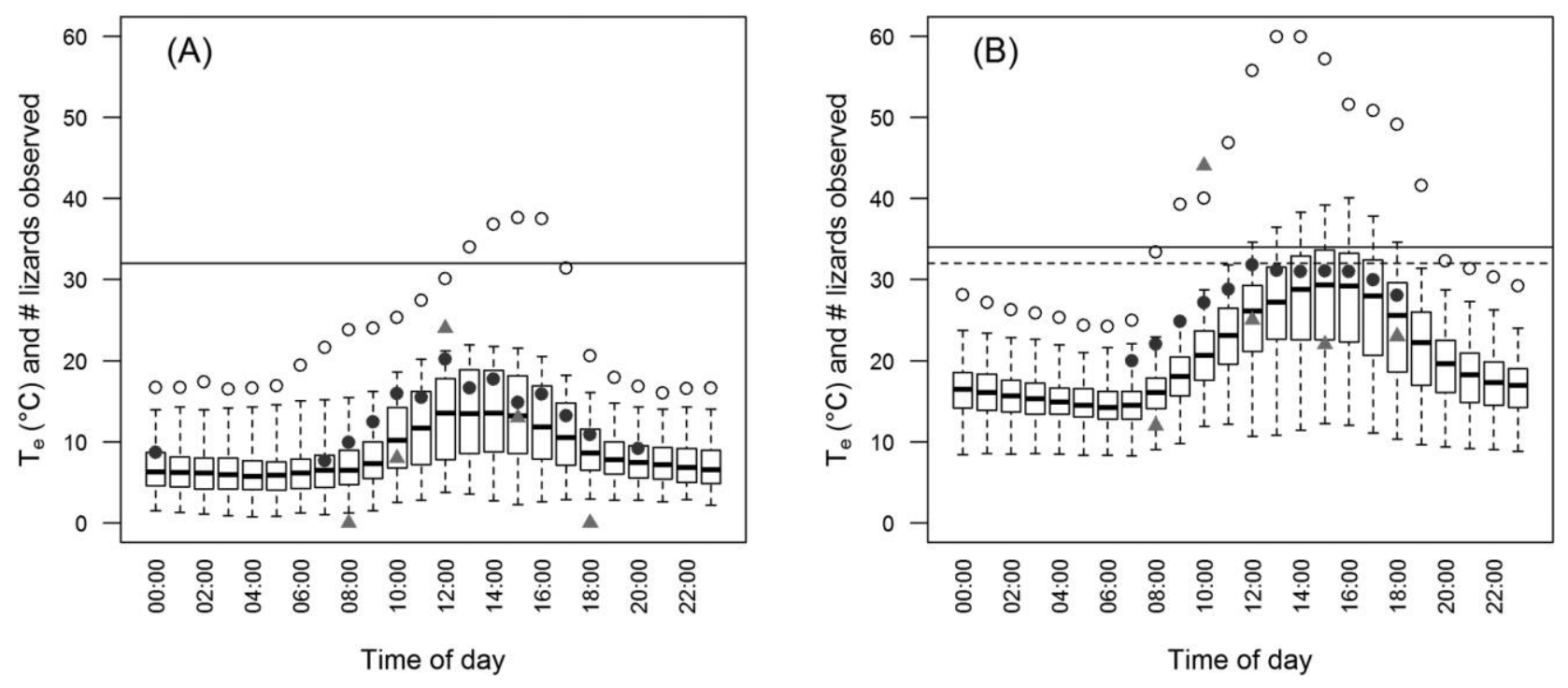

Figure 3. Operative temperatures $\left(T_{\mathrm{e}}\right.$ ) in winter (June-August 2011;A) and summer (January-March 2012; B). Boxes represent median and quartile $T_{\mathrm{e}}$, with whiskers set at maximum and minimum values. Open circles indicate absolute maximum $T_{\mathrm{e}}$. In $A$, the solid line is the mean $T_{\text {pref }}$ of winter lizards from all three acclimations. The solid and dotted lines in $B$ are the mean $T_{\text {pref }}$ for summer cold- and warm-acclimated lizards, respectively. Triangles indicate the number of lizards observed on a sunny day in winter $(A)$ and summer $(B)$ during transect surveys. Filled circles (using same $Y$-axis as $T_{\mathrm{e}}$ ) indicate the mean body temperature measured at the same site for six to 10 lizards equipped with lightweight radio transmitters during $5 \mathrm{~d}$ typical of summer and winter (Clusella-Trullas et al. 2009). A color version of this figure is available online.

predicting the realized plasticity of functional traits and, thus, the degree of evolutionary change these organisms may need in order to counteract rapidly changing climates and altered environments (Chevin et al. 2010; Reed et al. 2011; Paaijmans et al. 2013).

The variation in trait responses observed in Cordylus oelofseni may be interpreted as being beneficial from an evolutionary fitness perspective. For example, in summer there is a small but significant reduction of $T_{\text {pref }}$ in lizards acclimated to the warm treatment $\left(30^{\circ} \mathrm{C}\right)$. This pattern has been found in other species (e.g., Wilhoft and Anderson 1960; Li et al. 2009), although in most studies, mean $T_{\text {pref }}$ increases at higher acclimation temperatures (reviewed in Clusella-Trullas and Chown 2014). Since $T_{\text {pref }}$ is relatively close to $\mathrm{CT}_{\max }$ in $C$. oelofseni $\left(40.8^{\circ} \mathrm{C}\right.$; Clusella-Trullas et al. 2009) and is typical of other ectotherms (e.g., reviewed in Angilletta 2009), exposure to elevated temperatures for extended periods of time can result in compensation behavior that reduces the risk of overheating or accumulated heat stress (Huey and Bennett 1990; Martin and Huey 2008; Sinervo et al. 2010). Also, a significantly lower absolute voluntary thermal maximum (instead of mean or max $T_{\text {pref }}$ ) in the thermal gradient in warm-acclimated lizards compared with those acclimated at cold temperature adds supports to this safety mechanism (Heatwole 1976; see fig. A2). This behavioral shift in C. oelofseni cannot be associated with thermal constraints in their natural habitat, given the high thermal quality of the habitat found in summer (low $\bar{d}_{\mathrm{e}}$; fig. $3 B$ ). Alternatively, given the temperature dependence and lack of acclimation of RMR in summer (fig. 1), this response is likely to contribute to the maintenance of lower metabolic costs in peak summer season, reflecting an integration of behavioral and physiological responses.

In winter, C. oelofseni is highly constrained by the thermal quality of the habitat (high $\bar{d}_{\mathrm{e}}$; fig. $3 A$ ), but lizard activity patterns and prey diversity and abundance in the field demonstrate that C. oelofseni remains active in winter and has available food resources. The RMR responses documented here follow a partial compensation (Precht type 3 response; Precht 1958): lizards from the cold-acclimated group had an elevated RMR at the highest test temperature, with no compensation at the lowest test temperature. Increased RMR likely allows $C$. oelofseni to utilize thermal windows of opportunity throughout winter (see, e.g., Hare et al. 2010). Although the thermal quality of the habitat is low in winter, warm days are scattered throughout the season, and these recurring opportunities, albeit unpredictable, may form part of the information acquired by these organisms. Increased metabolism (perhaps regulated via thyroid hormone; Little et al. 2013) may enable rapid cellular responses to enhance performance in changing environmental conditions (Clarke and Fraser 2004). Indeed, metabolic cold compensation has been reported for other temperate species that remain active in winter (Roberts 1968; Dutton and Fitzpatrick 1974; Davies et al. 1981; Tsuji 1988b). Furthermore, RMR winter responses were partially in line with beneficial acclimation (Leroi et al. 1994; for alternative acclimation hypotheses, see ClusellaTrullas et al. 2010) because RMR was minimized at the temperature that most closely matched the acclimation temperature 
(but not at the intermediate test temperature of $20^{\circ} \mathrm{C}$; fig. 1). These responses could also suggest that lizards optimize metabolic efficiency (i.e., lower their RMR but increase their metabolic scope) in response to their thermal history by changes in membrane composition and oxidative capacity (Hochachka and Somero 2002; Guderley 2004; Seebacher et al. 2010). Although we cannot pinpoint the underpinning mechanism here, we found clear plastic responses in RMR in winter, while shortterm exposure to the three temperature regimes did not influence $T_{\text {pref }}$. Despite the limited thermal opportunities in their habitat in winter, lizards consistently seek $32^{\circ} \mathrm{C}$ when conditions allow.

In addition to short-term plastic responses, seasonal acclimatization of all traits was found. RMR in winter was higher than in summer when all acclimation treatments were compared at $30^{\circ} \mathrm{C}$ (the temperature closest to $T_{\text {pref }}$ ), while $T_{\text {pref }}$ and WLR were lower in winter. These responses may reflect distinct differences in energetic demands between seasons. Activity during transient warm weather and the usage of available resources in winter may require metabolic compensation and, thus, increased costs to optimize energy throughput during cold conditions (i.e., increased intake hypothesis; Burton et al. 2011). However, lower RMR in summer could also reflect a form of compensation to decrease metabolic costs at high temperatures (Tsuji 1988a) or changes in the partitioning of energy allocation to maintenance, growth, and reproduction (Congdon et al. 1982; Dunham et al. 1989). Similarly, shifts in $T_{\text {pref }}$ likely accompany the optimum temperature at which performance and underlying biochemical processes operate. For metabolism, it is difficult to discern between compensatory strategies (i.e., higher RMR in winter or lower RMR in summer) without exploring the relative costs and benefits relating to each strategy (e.g., energy budget including maintenance and production demands) and investigating underlying molecular and cellular mechanisms (Seebacher 2005). However, this study demonstrates that these compensatory responses are apparent only when comparing temperature exposures that are ecologically relevant to their respective seasons, since the comparison of the acclimation temperature of $20^{\circ} \mathrm{C}$ common to both seasons resulted in similar RMRs (table 3).

The increase in WLR in summer compared with winter when tested at $30^{\circ} \mathrm{C}$ is perhaps initially puzzling, given that this response was counter to that of RMR and that compensation for water loss would be expected to occur during the driest conditions of the year (Bentley and Schmidt-Nielsen 1966; Mautz 1982; Dmi'el et al. 1997). However, the population of C. oelofseni studied is restricted to mountain tops where orographic fog is frequent in both summer and winter, with mean daytime relative humidity of $68.79 \% \pm 0.61 \%$ and $69.82 \% \pm 0.82 \%$ during summer and winter, respectively (weather station data from winter 2011 and summer 2012). Therefore, these lizards may have limited scope for restricting water loss in dry and warm conditions. The increased WLR for summer-collected lizards may result from associated traits other than metabolism, such as behavioral mechanisms (e.g., panting for evaporative cooling; Tattersall et al. 2006) or seasonal changes in cutaneous properties (Mautz 1982). The plastic response of lizard WLR and of its components (cutaneous vs. respiratory) thus merits further research (Lillywhite 2006).

In addition to the contrasting responses in the short-term and seasonal scales reported here, considerable variation was found depending on the trait examined. In contrast to RMR and $T_{\text {pref }}$ responses, WLR responses appear less flexible in the short-term and across the full range of treatment conditions investigated here, irrespective of season. Therefore, these results highlight the importance of incorporating both behavioral and physiological plasticity into models that aim to predict the ability of ectotherms to tolerate climate variation or determine evolutionary fitness costs of weather transients (e.g., Dillon et al. 2007). Most likely, the challenge will be to integrate the magnitude, direction, and fitness consequences of plastic responses of multiple traits that may underlie competing functions in order to predict the consequences of global environmental change.

\section{Acknowledgments}

We are grateful to CapeNature for providing collection permits (AAA07-00318-0035,0035-AAA-004-000414-16, AAA00700425\&27-0035) in the Hottentots Holland Nature Reserve. We thank Philip Matthews and several anonymous reviewers who provided constructive comments on an earlier version of this manuscript. C.H.B. was supported by a bursary from the HOPE Project at Stellenbosch University. Funding was provided by the Centre for Invasion Biology and the Incentive Funding for Rated Researchers from the South African National Research Foundation to S.C.-T.

\section{Literature Cited}

Angilletta M.J. 2009. Thermal adaptation: a theoretical and empirical synthesis. Oxford University Press, New York.

Angilletta M.J., A.F. Bennett, H. Guderley, C.A. Navas, F. Seebacher, and R.S. Wilson. 2006. Coadaptation: a unifying principle in evolutionary thermal biology. Physiol Biochem Zool 79:282-294.

Angilletta M.J., T. Hill, and M.A. Robson. 2002. Is physiological performance optimized by thermoregulatory behavior? a case study of the eastern fence lizard, Sceloporus undulatus. ITherm Biol 27:199-204.

Bentley P.J. and K. Schmidt-Nielsen. 1966. Cutaneous water loss in reptiles. Science 151:1547-1549.

Burnham K.P. and D.R. Anderson. 2001. Kullback-Leiber information as a basis for strong inference in ecological studies. Wildl Res 28:111-119.

Burton T., S.S. Killen, J.D. Armstrong, and M.B. Metcalfe. 2011. What causes intraspecific variation in resting metabolic rate and what are its ecological consequences? Proc R Soc B 278:3465-3473. 
Case T.J. 1976. Seasonal aspects of thermoregulatory behaviour in the chuckwalla, Sauromalus obesus (Reptilia, Lacertilia, Iguanidae). LHerpetol 10:5-95.

Chevin L.-M., R. Lande, and G.M. Mace. 2010. Adaptation, plasticity, and extinction in a changing environment: towards a predictive theory. PLoS Biol 8(4):e1000357.

Christian K. and B. Green. 1994. Seasonal energetics and water turnover of the frillneck lizard (Chlamydosaurus kingii) in the wet-dry tropics of Australia. Herpetologica 50:274-281.

Clarke A. 1993. Seasonal acclimatization and latitudinal compensation in metabolism: do they exist? Funct Ecol 7:139-149.

- 2003. Costs and consequences of evolutionary temperature adaptation. Trends Ecol Evol 18:573-581.

Clarke A. and K.P.P. Fraser. 2004. Why does metabolism scale with temperature? Funct Ecol 18:243-251.

Claussen D.L. 1967. Studies of water loss in two species of lizards. Comp Biochem Phvsiol 20:115-130.

Clusella-Trullas S. and A. Botes. 2007. Faecal analysis suggests generalist diets in three species of Western Cape cordylids. Afr Zool 43:125-130.

Clusella-Trullas S. and S.L. Chown. 2014. Lizard thermal trait variation at multiple scales: a review. 1 Comp Physiol B 184 : 5-21.

Clusella-Trullas S., J.S. Terblanche, and S.L. Chown. 2010. Phenotypic plasticity of locomotion performance in the seed harvester Messor capensis (Formicidae). Physiol Biochem Zool 83:519-530.

Clusella-Trullas S., J.H. van Wyk, and J.R. Spotila. 2009. Thermal benefits of melanism in cordylid lizards: a theoretical and field test. Ecology 90:2297-2312.

Congdon J.D., R.E. Ballinger, and K.A. Nagy. 1979. Energetics, temperature and water relations in winter aggregated Sceloporus jarrovi (Sauria: Iguanidae). Ecology 60:30-35.

Congdon J.D., A.E. Dunham, and D.W. Tinkle. 1982. Energy budgets and life histories of reptiles. Pp. 233-271 in C. Gans, ed. Biology of the Reptilia. Academic Press, New York.

Cowles R.B. and C.M. Bogert. 1944. A preliminary study of the thermal requirements of desert reptiles. Bull Am Mus Nat Hist 83:261-296.

Crawley M. J. 2007. The R book. Wiley, West Sussex.

Davies P.M.C., J.W. Patterson, and E.L. Bennett. 1981. Metabolic coping strategies in cold tolerant reptiles. L Therm Biol 6:321-330.

Deutsch C.A., J.J. Tewksbury, R.B. Huey, K.S. Sheldon, C.K. Ghalambor, D.C. Haak, and P.R. Martin. 2008. Impact of climate warming on terrestrial ectotherms across latitude. Proc Natl Acad Sci USA 105:6668-6672.

DeWitt T.J., A. Sih, and D. Sloan Wilson. 1998. Costs and limits of phenotypic plasticity. Trends Ecol Evol 13:77-81.

Dillon M.E., L.R.Y. Cahn, and R.B. Huey. 2007. Life history consequences of temperature transients in Drosophila melanogaster. LExp Biol 210:2897-2904.

Dmi'el R., G. Perry, and J. Lazell. 1997. Evaporative water loss in nine insular populations of the lizard Anolis cristatellus group in the British Virgin Isles. Biotropica 29:111-116.
Dunham A.E., B.W. Grant, and K.L. Overall. 1989. Interfaces between biophysical and physiological ecology and the population ecology of terrestrial vertebrate ectotherms. Physiol Zool 62:335-355.

Dutton R.H. and L.C. Fitzpatrick. 1974. Metabolic compensation to seasonal temperatures in the rusty lizard, Sceloporus olivaceus. Comp Biochem Physiol A 51:309-318.

Fogel G. 2003. The art of armadillo lizards (Cordylus cataphractus): fifteen years of captive observations. Bull Chic Herpetol Soc 38:113-119.

Glanville E.J. and F. Seebacher. 2006. Compensation for environmental change by complementary shifts of thermal sensitivity and thermoregulatory behaviour in an ectotherm. LExp Biol 209:4869-4877.

Guderley H. 2004. Metabolic responses to low temperature in fish muscle. Biol Rev 79:409-427.

Gvoždík L. 2012. Plasticity of preferred body temperatures as means of coping with climate change? Biol Lett 8:262-265.

Hadamová M. and L. Gvoždík. 2011. Seasonal acclimation of preferred body temperature improves the opportunity for thermoregulation in newts. Physiol Biochem Zool 84:166174.

Hare K.M., S. Pledger, M.B. Thompson, J.H. Miller, and C.H. Daugherty. 2010. Nocturnal lizards from a cool-temperate environment have high metabolic rates at low temperatures. L Comp Physiol B 180:1173-1181.

Heatwole H. 1976. Reptile ecology. University of Queensland Press, St. Lucia.

Hertz P.E., R.B. Huey, and E. Nevo. 1983. Homage to Santa Anita: thermal sensitivity of sprint speed in agamid lizards. Evolution 37:1075-1084.

Hertz P.E., R.B. Huey, and R.D. Stevenson. 1993. Evaluating temperature regulation by field-active ectotherms: the fallacy of the inappropriate question. Am Nat 142:796-818.

Hochachka P.W. and G.N. Somero. 2002. Biochemical adaptation: mechanism and process in physiological evolution. Oxford University Press, New York.

Huey R.B. and A.F. Bennett. 1987. Phylogenetic studies of coadaptation: preferred temperatures versus optimal performance. Evolution 41:1098-1115.

. 1990. Physiological adjustments to fluctuating thermal environments: an ecological and evolutionary perspective. Pp. 37-59 in R. I. Morimoto, A. Tissieres, and C. Georgopoulos, eds. Stress proteins in biology and medicine. Cold Spring Harbor Laboratory Press, New York.

Huey R.B., C.A. Deutsch, J.J. Tewksbury, L.J. Vitt, P.E. Hertz, H.J. Álvarez Pérez, and T. Garland. 2009. Why tropical forest lizards are vulnerable to climate warming. Proc R Soc B 276:1939-1948.

Huey R.B., P.E. Hertz, and B. Sinervo. 2003. Behavioural drive versus behavioural inertia in evolution: a null model approach. Am Nat 161:357-366.

Huey R.B. and M. Slatkin. 1976. Costs and benefits of lizard thermoregulation. Q Rev Biol 51:363-384.

Kaufmann J.S. and A.F. Bennett. 1989. The effect of temperature and thermal acclimation on locomotor perfor- 
mance in Xantusia vigilis, the desert night lizard. Physiol Zool 62:1047-1058.

Kingsolver J.G. and R.B. Huey. 1998. Evolutionary analyses of morphological and physiological plasticity in thermally variable environments. Am Zool 38:545-560.

Lee J.C. 1980. Comparative thermal ecology of two lizards. Oecologia 44:171-176.

Leroi A., A.F. Bennett, and R.E. Lenski. 1994. Temperature acclimation and competitive fitness: an experimental test of the beneficial acclimation assumption. Proc Natl Acad Sci USA 91:1917-1921.

Li H., Z. Wang, W. Mei, and X. Ji. 2009 Temperature acclimation affects thermal preference and tolerance in three Eremias lizards (Lacertidae). Curr Zool 17:258-265.

Licht P. 1964. The temperature dependence of myosinadenosinetriphosphatase and alkaline phosphatase in lizards. Comp Biochem Physiol 12:331-340.

Lighton J.R.B. 2008. Measuring metabolic rates: a manual for scientists. Oxford University Press, New York.

Lillywhite H.B. 2006. Review: water relations of tetrapod integument. L Exp Biol 209:202-226.

Little A.G., T. Kunisue, K. Kannan, and F. Seebacher. 2013. Thyroid hormone actions are temperature-specific and regulate thermal acclimation in zebrafish (Danio rerio). BMC Biol 11:26.

Losos B.L., T.W. Schoener, and D.A. Spiller. 2004. Predatorinduced behaviour shifts and natural selection in fieldexperimental lizard populations. Nature 432:505-508.

Martin T.L. and R.B. Huey. 2008. Why "suboptimal" is optimal: Jensen's inequality and ectotherm thermal preferences. Am Nat 171:E102-E118.

Mautz W.J. 1982. Correlations of both respiratory and cutaneous water losses of lizards with habitat aridity. I Comp Physiol B 149:25-30.

McNab B.K. 2002. The physiological ecology of vertebrates: a view from energetics. Cornell University Press, Ithaca, NY.

Mouton P.F.N. and J.H. van Wyk. 1990. Taxonomic status of the melanistic forms of the Cordylus cordylus complex (Reptilia: Cordylidae) in the south-western Cape, South Africa. S Afr I Zool 25:31-38.

Paaijmans K.P., R.L. Heinig, R.A. Seliga, J.I. Blanford, S. Blanford, C.C. Murdock, and M.B. Thomas. 2013. Temperature variation makes ectotherms more sensitive to climate change. Global Change Biol 19:2373-2380.

Pinheiro J., D. Bates, S. DebRoy, D. Sarkar, and the R Development Core Team. 2013. nlme: linear and nonlinear mixed effects models. R package. Version 3.1-111.

Precht H. 1958. Concepts of temperature adaptation of unchanging reaction systems of cold-blooded animals. Pp. 5078 in C.L. Prosser, ed. Physiological adaptation. American Physiological Society, Washington, DC.

R Development Core Team. 2008. R: a language and environment for statistical computing. R Foundation for Statistical Computing, Vienna.
Reed T.E., D.E. Schindler, and R.S. Waples. 2011. Interacting effects of phenotypic plasticity and evolution on population persistence in a changing climate. Conserv Biol 25:5663.

Roberts L.A. 1968. Oxygen consumption in the lizard Uta stansburiana. Ecology 49:809-819.

Rogers K.D., M.B. Thompson, and F. Seebacher. 2007. Beneficial acclimation: sex specific thermal acclimation of metabolic capacity in the striped marsh frog (Limnodynastes peronii). LExp Biol 210:2932-2938.

Seebacher F. 2005. A review of thermoregulation and physiological performance in reptiles: what is the role of phenotypic flexibility? L Comp Physiol B 175:453-461.

Seebacher F., M.D. Brand, P.L. Else, H. Guderley, A.J. Hulbert, and C.D. Moyes. 2010. Plasticity of oxidative metabolism in variable climates: molecular mechanisms. Physiol Biochem Zool 83:721-732.

Sinervo B., F. Méndez-de-la-Cruz, D.B. Miles, B. Heulin, E. Bastiaans, M.V.-S. Cruz, R. Lara-Resendiz, et al. 2010. Erosion of lizard diversity by climate change and altered thermal niches. Science 328:894-899.

Somero G.N. 1978. Temperature adaptations of enzymes: biological optimisation through structure-function compromises. Annu Rev Ecol Syst 9:1-29.

. 2010. The physiology of climate change: how potentials for acclimatization and genetic adaptation will determine "winners" and "losers". I Exp Biol 213:912-920.

Tattersall G.J., V. Cadena, and M.C. Skinner. 2006. Respiratory cooling and thermoregulatory coupling in reptiles. Respir Physiol Neurobiol 154:302-318.

Tsuji J.S. 1988a. Seasonal profiles of standard metabolic rate of lizards (Sceloporus occidentalis) in relation to latitude. Physiol Zool 61:230-240.

. 1988b. Thermal acclimation of metabolism in Sceloporus lizards from different latitudes. Physiol Zool 61:241253.

Wheeler P.E. 1986. Thermal acclimation of metabolism and preferred body temperature in lizards. ITherm Biol 11:161166.

Wilhoft D.C. and J.D. Anderson. 1960. Effect of acclimation on the preferred body temperature of the lizard, Sceloporus occidentalis. Science 131:610-611.

Woods H.A. and J.F. Harrison. 2001. The beneficial acclimation hypothesis versus acclimation of specific traits: physiological change in water-stressed Manduca sexta caterpillars. Physiol Biochem Zool 74:32-44.

Zuur A.F., E.N. Ieno, N.J. Walker, A.A. Saveliev, and G.M. Smith. 2009. Mixed effects models and extensions in ecology with R. Springer, New York.

Zytynska S.E., M.F. Fay, D. Penney, and R.F. Preziosi. 2011. Genetic variation in a tropical tree species influences the associated epiphytic plant and invertebrate communities in a complex forest ecosystem. Philos Trans R Soc B 366:1329-1336. 